\title{
APRESENTAC, ÃO
}

A revelação da experiência estética não precisa de uma formulação utópica, porque as obras de arte alcançadas não prometem a satisfação de um requisito absoluto de significado, mas nosso enriquecimento cognitivo em um sentido amplo. Trata-se de experimentar esteticamente o presente precário de nossa liberdade finita, não seu futuro ilusório. Quem quer liberdade também deve querer as decepções da experiência. Portanto, o conhecimento estético não substitui o pensamento conceitual fracassado. As virtualidades da experiência estética são as de uma crítica à experiência curta, omitida, escassa, reprimida.

- Daniel InNerarity

O dossiê Experiências Estéticas Contemporâneas tem como propositura debater acerca das dimensões estéticas entre o século XIX e o século XX, especialmente a partir das expressões produzidas pelas linguagens artísticas (literatura, cinema e música) e suas respectivas performances.

Consideramos a estética como uma modalidade cognitiva legítima capaz de acessar a realidade a partir de verbos criativos como o sentir, querer e pensar, o que caracterizaria o processo compreensivo da realidade proposto por Dilthey em Vida Y Poesia (1945). A estética, como remonta Susan Buck-Morss (2012, p. 157), em sua etimologia carrega consigo a dimensão corpórea, sinestésica - trata-se da percepção pela via sensorial - não restrita somente a arte, beleza e verdade, como os modernos quiseram, mas na captação da realidade em sua natureza material e corpórea, enquanto uma forma de cognição da vida.

Assim, nesse dossiê, nós organizadores, quisemos angariar textos que trouxessem à tona o potencial político de captação compreensiva da experiência social e política da cultura, a partir de aspectos caros a estética como profundidade, aparência, forma, conteúdo e, sobretudo, as mediações elaboradas pelos efeitos teóricos e práticos da relação entre arte, cultura e sociedade. Especialmente em um contexto em que a arte e a cultura tem sido alvo de ataques políticos e a estética é apropriada pela política, o que tem proporcionado, para setores conservadores, um efeito de satisfação artística no campo político e, por conseguinte, fazendo com que a arte busque empreender a politização de suas performances para enfrentar esses efeitos autoritários.

Esse "cogito" foi bem localizado por Walter Benjamin, no século XX, acerca dessas inserções da estética entre as práticas políticas do fascismo e os anseios do comunismo diante da obra de arte e sua reprodutibilidade técnica. Talvez, a esperança de Benjamin, em tal constatação, estivesse na relação ética entre arte e política, o que configura uma tarefa árdua para a estética na contemporaneidade que, segundo Buck-Morss, consiste em

desfazer a alienação do sensório corporal, restaurar a força instintiva dos sentidos corporais humanos em prol da autopreservação da humanidade, e fazê-lo não evitando as novas tecnologias, mas perpassando-as. (BUCK-MORSS, 2012, p. 156). 
Dessa feita, o nosso desejo se faz quase apologético acerca da estética, no sentido de que devemos pensar esteticamente e, sobretudo, investigar as produções culturais enquanto calcadas e atravessadas pela realidade, não como "elucubrações supralunares". No que se refere a dimensão estética da arte, concordamos com os pressupostos de Jauss e a estética da recepção, apontados por Daniel Innerarity, em que a "estética acentua de maneira particular a historicidade e o caráter público da arte, ao situar em sua centralidade o sujeito que percebe e o contexto em que elas são recebidas" (INNERARITY, 2002, p. 09). Interessa-nos aqui os processos históricos de significação, de atribuição de sentido e, como a estética trata do ordenamento cognitivo das possibilidades de estranhamento das formas de perceber a vida, bem como "daquelas que já foram vivas em alguma vez, ordenando-as de novo" (LUCKÁCS apud MACHADO, 2004, p. 12). Trata-se de pensar a forma (a vida dotada de sentido ético e estético), enquanto "absoluto em relação à caótica vida cotidiana" (MACHADO, 2004, p. 19).

As experiências estéticas são um campo aberto de experimentações de liberdade e fracassos capazes de, historicamente, renovarem e produzirem diversos sentidos às nossas formas de perceber a realidade em suas múltiplas interfaces. Nesse sentido, como aponta Daniel Innerarity, na introdução de Pequena apologia de la experiência estética, de Jauss:

A obra de arte alcançada oferece, aqui e agora, possibilidades de um encontro libertador com a própria experiência. Essa experiência reflexiva transgride as convenções da ação cotidiana, mas não para negar, em princípio, seu escopo e suas limitações, mas medir-se de forma modificável com as possibilidades e limites dessa prática. (INNERARITY, 2002, p. 24)

Diante desse propósito de pensar as experiências estéticas enquanto possibilidades abertas de atribuição e transformação de sentido ao longo do tempo, o presente dossiê é formado por seis artigos de pesquisadores que, de alguma maneira, lidam com objetos estéticos em sua dimensão histórica. O primeiro bloco se destina a experimentar análises acerca da relação entre estética e literatura, lidando com proposições estéticas em obras de Paul Celan, Charles Baudelaire, Francisco Candido Xavier e Nelson Rodrigues. O segundo bloco se incumbe de investigar as relações estéticas entre a crítica, história e cinema. O terceiro bloco se encarrega de pensar a estética musical.

Em a Neve das Palavras, texto que abre o dossiê e seu respectivo primeiro bloco, Maria João Cantinho trata da vida do poeta, romeno radicado na França, Paul Celan e, por conseguinte, analisa como os protocolos e referenciais de leitura dele desenvolveram uma "simultaneidade" estética entre política e literatura que, de certa forma, reverberaram em sua poesia. Para Celan, o poema, em sua dimensão estética encarnada na linguagem, é a forma em que as possibilidades "são um caminho: encaminham-se para um destino para um lugar aberto, para um tu intocável" (CELAN, 1996, p. 34). Nessa esteira da poesia, Marcos Antonio de Menezes, em DANDY: UmA CRIAÇÃo dAs METRÓPOLES NOVECENTISTAS, se acerca de compreender como se constrói a figura do Dândi, como aquele que desnuda e experimenta a vida parisiense em seus ápices de modernidade, no século XIX, sob as letras da escrita de Charles Baudelaire.

Ainda sobre os aspectos da literatura, mas sob a égide dos processos de recepção e circu- 
lação, Ana Lorym Soares, em Circulação E RecepÇão Da Literatura Psicografada A Partir Da Coleção A Vida No Mundo Espiritual (1944-1968), De Chico Xavier, mapeia e interpreta dentro de uma comunidade específica de leitores qual o percurso de significação que os romances psicografados por Chico Xavier e editados pela Federação Espírita Brasileira (FEB), na coleção A vida no mundo espiritual (1944-1968), percorreram historicamente. Isso, a partir das nuances do romance, história e ficção diante de determinado público leitor.

Em O Verdadeiro Casamento Rodriguiano: Apontamentos Sobre Amor E Desejo No Romance O Casamento (1966) De Nelson Rodrigues, Lays da Cruz Capelozi empreende notas analíticas sobre o único romance escrito por Rodrigues, a fim de abordar temas como amor e desejo, a partir da inferência da moral religiosa cristã quanto ao funcionamento do matrimônio. O livro analisado pela autora foi lançado em 1966, e figurava para Nelson Rodrigues como uma defesa ao casamento, mas para os censores tratou-se de uma crítica à família burguesa. Assim, percebe-se que os processos de significações que extrapolam o desejo do autor ao longo do tempo.

O segundo bloco se restringe ao artigo O CLÁSSICO E O MODERNO: EISENSTEIN E ORSON Welles na Pena de Paulo Emílio Sales Gomes, de Rafael Morato Zanatto, que trata como as categorias de clássico e moderno são empreendidas pelo crítico e historiador Paulo Emílio Sales Gomes acerca do fenômeno cinematográfico, especialmente a partir de sua profícua atenção às produções estéticas do cineasta russo Serguei Eisenstein e do estadunidense Orson Welles. Nesse ensejo, Zanatto aponta que Paulo Emílio forjou um método próprio, capaz de condensar no âmbito da crítica e da história um procedimento que concilia o estudo da linguagem, do estilo e da expressão social das produções cinematográficas.

O último bloco conta com o texto que encerra o dossiê, DrogAS, FESTIVAIS E Rock NA IMPRENSa Brasileira E Portuguesa - 1970/1975, de Paulo Gustavo da Encarnação. O autor articula música, eventos musicais - os festivais - e as drogas para compreender como esses elementos se tornaram um fenômeno de escala mundial e, conseguintemente, atraíram a atenção das imprensas brasileira e portuguesa. Dessa maneira, analisa como os veículos de imprensa abordaram, em suas respectivas páginas, a relação entre drogas, festivais e rock no período compreendido entre 1970 a 1975. Não obstante, apresenta a dimensão social, cultural e política dos festivais roqueiros em tempos de ditaduras, tanto em terras brasileiras quanto portuguesas.

Com a publicação do dossiê Experiências Estéticas Contemporâneas, a albuquerque: revista de história cumpre, mais uma vez, a sua proposta de divulgar os trabalhos de pesquisadores nacionais e estrangeiros,estabelecendo com os mesmos um diálogo de caráter interdisciplinar que configura o propósito do Programa de Pós-graduação em Estudos Culturais da UFMS/CPAq que, inclusive, propõe em suas linhas de pesquisa reflexões sobre a estética acerca dos marcadores da diferença, identidade, etc.

Aquidauana, dezembro de 2019

Organizadores:

Marcos Antonio de Menezes (UFJ)

Rafael Morato Zanatto (Doutor pela Unesp-Assis)

Robson Pereira da Silva (Doutorando em História pelo PPGHI/UFU) 


\section{REFERÊNCIAS:}

BUCK-MORSS, Susan. Estética e anestética: uma reconsideração de A obra de arte de Walter Benjamin. In: BENJAMIN, Walter; SCHÖTTKER, Detlev; BUCK-MORSS, Susan. Benjamin e a obra de arte: técnica, imagem, percepção. Rio de Janeiro: Contraponto, 2012.

CELAN, Paul. Arte poética: O Meridiano e outros textos. Lisboa: Cotovia, 1996.

DILTHEY, Wilhelm. Vida y poesia. México: Fundo de Cultura Econômica, 1945.

INNERARITY, Daniel. Introdución. In: JAUSS, Hans Robert.Pequeña apología de la experiencia estética. Barcelona: Ediciones Paidós, 2002.

MACHADO, Carlos Eduardo Jordão. As formas e a vida: Estética e ética no jovem Luckács (19101918). São Paulo: Editora UNESP, 2004. 